\title{
Reduction of Post-Harvest Losses: A Gateway to Improving Livelihood of Smallholder Farmers and Ensuring Food Security in Nigeria
}

\author{
Zhenling Cui ${ }^{1} \quad$ Lawal Olusola Lawal $^{1,2}$ \\ 1. College of Resource Utilization and Environmental Sciences, China Agricultural University, Beijing, China \\ 2. Federal department of extension, Federal Ministry of agriculture and Rural Development Abuja, Nigeria
}

\begin{abstract}
Nigerian smallholder farmers suffer huge losses on annual basis in terms of monetary value as a result of postharvest losses due to factors such as inadequate storage/processing facilities, poor transportation system, lack of power supply and unorganized marketing network. With the largest population on the African continent and a spiraling increase, a corresponding increase in food supply is inevitable. The food security situation in Nigeria is already challenged by a growing pressure on land and water resources due to population increase, farmersherders clashes and terrorism which has adversely disrupted farming activities particularly in the northeastern part of the country. With all these challenges, high loss of farm produce due to post-harvest loss is indeed another great threat to the attainment of food security in Nigeria. This paper focused primarily on postharvest losses which are like a recurring decimal in Nigeria's agricultural sector, it discussed the driving factors, highlights its impacts and suggest some viable solutions and measures that can be adopted to tackle the problem with a view of increasing farmer's income and ensuring food security in Nigeria.
\end{abstract}

Keywords: Post-harvest loss, Smallholder farmers, Livelihood, Food security and Nigeria.

DOI: $10.7176 / \mathrm{JBAH} / 11-22-04$

Publication date: November $30^{\text {th }} 2021$

\subsection{Introduction}

Food is one of the most vital and basic need of life. It's a basic component of life regardless of class, belief or race. The quality and availability of food has a direct effect on the quality of life and well-being of an individual. Therefore, this is more reason why ensuring food security has always been a great concern to governments and agencies at all level all over the world. Presently, ensuring food security and feeding the ever growing world population are major concerns globally. In the face of challenges like climate change, global warming, desert encroachment and the loss of fertile arable land due to urbanization and other human activities other than agriculture, Post-harvest loss of farm produce pose another great threat to global food security.

A study by Fox and Fimeche (2013) reported that current agricultural practices use 4,931 million hectares of the total 14,894 million hectares of land surface on the earth. In addition, agricultural production uses 2.5 trillion $\mathrm{m} 3$ of water per year and over $3 \%$ of the total global energy consumption, and with estimated food losses of about $30-50 \%$ of total production. This translated to wasting 1.47-1.96 million hectares of arable land, 0.751.25 trillion $\mathrm{m} 3$ of water and 1-1.5\% of global energy. Every bit of farm produce saved from post-harvest losses translates into an added unit of food made available for productive utilization, including household consumption at a time when global food security is under threat from shrinking arable land and variation in climate change (Mbata, 2013).

Over the last few decades, Nigeria as the most populous African nation has been witnessing a continuous increase in population with a consequent increase in its demand for food. Due to this continuous increase in population, it is a fact that there will be a corresponding demand for land to be used for other purposes other than agriculture. In addition to the problems of low yield and low agricultural productivity, Nigeria also loses a lot of food in the post-harvest chain. Nigeria has suffered a tremendous loss of food products estimated at about 30$50 \%$ of production due to lack of proper and adaptable processing and storage facilities(Udoh, 2009).

Every year across sub-Saharan Africa (SSA) unacceptable levels of food loss continue to occur. Although these losses are being recorded at the various stages in the supply chain, from production through to retail and consumer levels, the area of highest concern (where the greatest percent of crop losses are recorded) are pre-farm gate, where poor harvesting, drying, processing and storage of crops occurs. Post- harvest management at farm level is the critical starting point in the supply chain(Management et al., 2014). Despite increased warnings regarding the planet's inability to feed the expected population growth beyond 2050. Alarmingly, very little is being done to preserve existing food production in regions most vulnerable. Over recent decades, significant focus and resources have been allocated to increase food production $(95 \%$ of all research investments over the past 30 years have focused on increasing productivity and only $5 \%$ directed towards reducing losses (Kader, 2005). The solution, however, requires more than an expansion of agricultural production. Improving farm management practices will not only increase the available food for consumption annually by millions of tonnes, 
but will achieve this without incurring the additional labour, land, materials, resources and biofuel expansion required with increased production(Management et al., 2014).

Agricultural produce pass through a lot of channels and processes such as harvesting, storage, transporting, processing and packaging before getting to the table of the final consumer. The cumulative of the losses that occur along all the channels food passes through before reaching the table of the final consumer is often regarded as post-harvest food loss. Due to so many factors such as lack of good storage and processing facilities, poor power supply, poor access and linkage roads and lack of modern post-harvest handling skills among farmers in Nigeria, a lot of agricultural produce; especially the perishables end up as wastes rather than table of consumers as a result of deterioration and spoilage. The principal role of an efficient post-harvest system is to ensure that the harvested product reaches the customer while satisfying the attributes of volume, quality, and safety(Raut $e t$ al., 2018). Therefore, post-harvest loss prevention stretches beyond ensuring good storage, preservation and processing, it extends to ensuring good transportation and distribution of produce to the point of sale.

A report by the World Bank (World Bank, 2011) revealed a huge volume of yearly loss of farm produce in Sub-Saharan Africa (SSA), the value of which is estimated at USD 4 billion for grains while the Food and Agriculture Organization of the United Nations (FAO) reported annual food losses in SSA exceeding 30\% of total crop production every year. Despite all the volume and the implication of these losses on food security of the region, this problem has not received the attention it deserves. Significant focus and resources have been allocated to increase food production $95 \%$ of all research investments over the past 30 years have focused on increasing productivity and only 5\% directed towards reducing losses(Kader, 2005).

Despite the large number of investigative papers written on the recurring post- harvest food losses in SSA, each providing recommendations as to how to resolve the problem, there is little evidence of the recommendations being acted upon(Joughin and Kjær, 2010). With food representing as much as $80 \%$ of household spending in SSA and crop production remaining the principal source of family income, the impact of eradicating these losses is massive(Tefera et al., 2011). Improving post-harvest management competencies amongst low-income farmers will not only lead to increased crop preservation and food volumes for consumption and trade, it has the potential to directly impacting on the health and well-being of all people living in the region(World, 2011). Therefore there must be deliberate efforts and attention towards sustainable food production and reducing PHL which has over the year's amount to billions of dollars in value. This will not only help the country save more food from waste and make the efforts in boosting food production visibly impactful, but also help in saving the resources such as land, water, fertilizer, pesticides, labor and time that goes into food production from wasting.

Reduction in post-harvest losses offers the particular advantage of increasing food availability without requiring additional land, water, labor, energy and agricultural inputs(Naziri et al., 2014). With more than 60\% of Nigerians employed in the agricultural sector, finding practical solutions to post-harvest losses will play a vital role in improving the livelihood of many and bring about a sustainable development in the sector(Abbas et al., 2018). In view of this, this paper therefore seeks to identify the drivers and the impact of PHL on farmer's income and food security in the country with the aim of suggesting practical solutions to all stakeholders (Government \& its agencies, policy makers, research institutes and farmers) involved on how to work together in solving this problem towards achieving food security.

\subsection{Magnitude Of Post-Harvest Losses In Nigeria}

Magnitude of postharvest losses in the food supply chain vary greatly among different crops, areas, and economies and in developing countries, people try to make the best use of the food produced, however, a significant amount of produce is lost in postharvest operations due to lack of knowledge, inadequate technology and/or poor storage infrastructure(Kumar and Kalita, 2017). In many African countries, the post-harvest losses of food cereals are estimated at $25 \%$ of the total crop harvested while losses in perishable crops such as fruits, vegetables and root crops, being less hardy than cereals reach about 50\% (Voices Newsletter, 2006).

Estimates of post-harvest food losses in the developing countries e.g. (Nigeria) from mishandling, spoilage and pest infestation are put at $25 \%$ which implies that one-quarter of what is produced never reaches the consumer(Bolarin and Bosa, 2015). Also Survey carried out on post-harvest food losses in some communities in Nigeria revealed that as much as $20-30 \%$ of total grain production, $30-50 \%$ of root and tuber and usually higher percentage of fruits and vegetables are lost with a substantial amount recorded during storage (Mijinyawa, Y. 2002).

\subsection{Drivers Of Post-Harvest Losses In Nigeria}

All crops are subject of deterioration or spoilage at different stage and time immediately it's been harvested. The moment a crop is harvested from the soil or detached from its parental stock, it commences deterioration(Campus et al., 2021). However, the rate and level of this damage is influenced by so many factors which are either internal or external environmental factors, farming practice, handling and the 
nature/perishability of the crop involved. Post-harvest losses are much higher for highly perishable products like fresh fruits, vegetables and some tubers than for cereals and other field crops. Due to their fragile nature and high water content, perishable crops and commodities have individual requirement with respect to temperature and other factors that must be provided for throughout the entire post-harvest chain.

Apart from high post-harvest loss of farm produce, food insecurity in Nigeria is a product of multidimensional factors such as: incessant communal conflicts. Most recently, insurgency and militant groups like Boko Haram and the violent attacks of the unregulated pastoral herders on crop farmers has further compounded the problem. On the other hand, it can also be attributed to lack of funding and incentives, poor and inconsistent policies, and low level of mechanization, poor infrastructure and rural development. The Post-harvest chain covers a whole lot of activities right from immediately harvesting to sorting, storage, transporting, processing to distribution. During all these processes and activities, farm produce are exposed to a lot of conditions and factors that causes or promote deterioration. Losses occur at different stages due to different factors, for example losses during harvesting are largely due to improper handling, early/late harvesting or bad tools while losses during storage are mostly due to pest, poor facilities and materials.

Most of the farming activities in Nigeria are done in the rural areas and due to the high deficit of amenities and infrastructure such as good access and linkage roads, power supply, modern storage and processing facilities. Consequently, all these contribute to a lot of the farm produce going to waste at the farm level due to difficulty to properly process, store or transport to city markets. It is a very sad reality that year-in and year-out, farmers in this part of the world work extra-hard to till the land and cultivate crops but most of the time could not guarantee that the harvest would make it to the market. The main causes of food losses and waste in low-income countries are connected to financial management and technical limitation in harvesting, storage and processing techniques(Mada et al., 2014).

Generally and globally, factors that cause post-harvest losses are usually categorized into primary and secondary causes. While the primary causes constitutes of factors that directly affects the crop or as a result of its composition, the secondary causes are mostly socio-economic factors that multiply the losses. The three main factors causing post-harvest losses, they are physiological, physical, and environmental factors. Major components of the environmental, physiological and physical factors causing post-harvest losses are high relative humidity and rain, uncontrolled fluctuating temperature, mechanical damage and crop adulteration causing by fungal and bacterial pathogens, inappropriate handling, attacking from birds, rodents, insect and other pests, storage and processing techniques leading to crop perishability (World Bank, 2011). Below are some of the socio-economic factors that fuel or contribute to postharvest losses in Nigeria:

- $\quad$ Poor And Inadequate Storage and Processing Facilities

This is probably one of the major problems facing agriculture and food security in Nigeria. Due to overdependence on rain fed farming, farmers harvest almost at the same time and this result to glut and wastage. Consequently, an appreciable percentage of these surplus farm produce during harvest season which should have been processed or stored for use at off-season are lost due to the unavailability of storage and modern processing facilities. Maintenance is another problem facing the public Infrastructures in Nigeria, some good storage facilities that were built for years ago are currently out of shape and service due to lack of maintenance (Bolarin and Bosa, 2015).

- Poor Transportation Network and System

Rural areas where majority of farming activities are done in Nigeria is characterized with lack of infrastructure like access and linkage roads that is needed in the smooth transportation of farm produce. Access roads to farms and the ones connecting rural communities to towns and cities are in a very bad shape; this situation has contributed greatly to the loss of farm produce as it takes extra cost, time and efforts to transport. Due to the bad condition of the roads, vehicles conveying farm produce to markets for sale break down or even get involved in terrible accidents leading to some of these produce being wasted before they reach the end users in different towns and cities across the nation(Abbas et al., 2018).

- $\quad$ Lack of Coordinated Market Linkage

Due to their small scale nature, smallholder farmers have lesser chance of selling product to a ready processor or off takers who buy in large quantities. Lack of access to a coordinated market further exposes small holder farmers to exploitation by middle men who take advantage of the poor/non-availability of storage and processing facilities to shortchange farmers.

- Low Level of Improved Technology

High cost of modern harvesting/processing equipment and the insufficient supply of locally fabricated ones has made the use of crude tools (such as cutlass, hoes, sickle) still very prevalent among smallholders farmers in Nigeria. This factors in its own way has also contributed to post-harvest losses by causing damages (cuts \& bruises) to crops (like yam, cassava, potatoes) making them susceptible to spoilage, insect, fungi and bacteria attacks.

- $\quad$ Lack Of Information and Skills In Post-Harvest Handling 
The place of having the right information and required set skills in post-harvest handling cannot be overemphasized. A good knowledge and skill on the best practice of harvesting, storage, packaging and transportation among smallholder farmers will go a long way in the reduction of the losses being experienced.

- Over Dependence on Weather Elements

As a result of unstable supply of electricity and unavailability/affordability of small-scale processing equipment, smallholder farmers rely mostly on sun drying of produce as a means of preservation. However, due to the unstable nature of weather elements, such produce and foodstuffs usually end up not properly dried or beaten by rain and these results to losses and contamination due to growth of molds and caking.

\subsection{Impact of Post-Harvest Loss}

Postharvest losses result in the wastage of resources such as land, water, fertilizer, herbicide, seeds, and seedlings and time that are used in the production of crops that are not consumed or utilized for other purposes(Abbas et al., 2018). PHL has a ripple effect that directly or indirectly affects all, be it farmers or consumer. These effects are felt by people across all sector of the economy. The direct impact of PHLs is on the livelihoods of farmers and other supply chain actors who depend solely on income from their produce for survival. The indirect impacts are on consumers because high losses in farm products results to escalating food prices(Justina, Hirawaty and Isima, 2019). In all, Post-harvest has a negative effect on food security, farmers' income and causes some environmental problem.

- Food Security

Postharvest loss accounts for both quantity and quality losses that reduce the economic value of crop, it results in shortage in harvested crop that gets to satisfy the hunger and food need of the final consumer. In African countries, these losses have been estimated to range between $20 \%$ and $40 \%$, which is highly significant considering the low agricultural productivity in several regions of Africa (Ndunguru, 2014).

- Farmers Income

Smallholder farmers suffer a great deal of economic loss as a result of post-harvest loss due to the position they occupy in the entire food chain network. The direct impact of PHLs is on the livelihoods of farmers and other supply chain actors who depend solely on income from their produce for survival (Justina, Hirawaty and Isima, 2019).

\section{- Resources Wastage}

Waste of farm produce without satisfying the purpose of feeding a final consumer is a complete waste of resources, time and effort that was employed in the entire production cycle. This includes land, capital used in purchasing of all inputs used, wages for labor and managerial efforts are all wasted on futility due to lack of storage/processing facilities and market for produce. This has a great financial implication especially to the poor smallholder in Nigeria as most of the money used is from their penury savings or sometimes from loan and this contributes to them unable to pay back. According to (FAO, 2013), globally, about 1.4 billion hectares of land were wasted by growing food that was not consumed in the year 2007, an area larger than Canada and China.

- Environmental Pollution

Farm produce that doesn't make it to the final consumer usually end up as dump hill causing environmental risks like bad smell, serving as a medium for breeding disease causing parasites and bacteria and even causing to the air and nearby water bodies. Also, carbon dioxide which is a major greenhouse gas contributing to global warming is generated from decomposing dump of farm produce. According to (Kumar and Kalita,2017), unutilized food also results in extra carbon dioxide (CO2) emissions, eventually affecting the environment

During harvest season, most agricultural produce in the country used to command low prices due to the glut in the market and this does not allow farmers to get good reward for their efforts in terms of labor and other resources invested in farming. Even at low prices, some farmers are still unable to sell their produce and as a result, most of them perish as there are inadequate modern storage facilities to store them coupled with the factor that Nigeria is a country that is bedeviled with epileptic power supply.

\subsection{Solution And Recommendations}

Although, it will be very difficult to achieve zero Post-harvest losses but efforts can be made to reduce it to a bearable minimum. Reduction in postharvest loss will not only increase food availability and boost food security in Nigeria; it is also a very potent way to improve the income and livelihood of smallholder farmers who grows the bulk of our foods.

Losses occur at the various levels of the post-harvest chain and it's due to numerous factors. In order to effectively tackle a problem of this nature, efforts and solutions must also be both multi-dimensional and multisectoral in nature. All active stakeholders and players in the food and agricultural space have a role to play in order to solve this problem.

Government

- Government should intensify efforts and investment in rural infrastructural facilities such as access and 
linkage roads, stable electricity and portable water

- Government should also put in place policies that will encourage the inclusion of local raw materials in processed goods

- Massive investment on agricultural research and extension service

- Government at levels should increase budgetary allocation to the agricultural extension service so as to allow them organize regular trainings, seminars and workshops for farmers on latest developments in agriculture and especially about latest post-harvest handling techniques/technology.

- Policies that will improve the access to agricultural loan and reduced interest loans

Research Institutes

- Research institution such as National Stored Product Research Institutes (NSPRI) and National Center for Agricultural Mechanization (NCAM) should increase on developing more affordable post-harvest technologies for smallholder farmers.

- Research institutes should also improve on the dissemination and awareness on best practices in postharvest handling among local smallholder farmers.

- Frequent training on improved processing and storage techniques should be organized for farmers.

Farmers

- Farmers should prioritize the formation and joining of farmer's co-operatives, this will allow them to achieve many things such as: easy access to credit and loan facilities, improved access to off-takers and better access to quality farm inputs at cheaper rates.

- Farmers should endeavor to always take advantage of training opportunities present and put information and skills acquired to use in their farming activities.

\section{Conclusion}

Waste of farm produce without meeting the purpose of satisfying hunger by feeding a final consumer is a complete waste of resources, time and effort that was employed in the entire production cycle. This includes land, capital used in purchasing of all inputs used, wages for labor and managerial efforts are all wasted on futility due to lack of storage/processing facilities and market for produce. This doesn't only threatens food security but also has a great financial implication especially to the poor smallholder in Nigeria as most of the money used is from their penury savings or sometimes from loan and this contributes to them unable to pay back.

Conclusively, every bit of food saved from loss is just like an additional food produced without cultivating or using any form of input. As a result of challenges like global warming, urbanization and ever-growing population of the country, there is a constant increase in demand for food and at the same time a decline in the area of lands available for agriculture. It is therefore evident that serious efforts must be made to reduce postharvest losses as a complementary move to improved and sustainable methods of food production. A great reduction in post-harvest losses of farm produce in Nigeria will not only improve the livelihood and income of smallholder farmers but also help the country in attaining of food security without necessarily having an increase in the area of land under cultivation.

\section{Acknowledgement}

This work was supported by the Bill \& Melinda Gates Foundation (OPP1209192) and the "Sino-Africa Friendship" China Government Scholarship (2019-1442).

\section{References}

Abbas, A. M. et al. (2018) 'REDUCING POSTHARVEST LOSSES IN NIGERIA' S PATHWAY TO SUSTAINABLE AGRICULTURE . AGRICULTURAL SECTOR :', 5(2), pp. 16-21.

Abass, A.B., Ndunguru, G., Mamiro, P., Alenkhe, B., Mlingi, N., Bekunda, M. Post-harvest food losses in a maize-based farming system of semi-arid savannah area of Tanzania. J. Stored Prod. Res. 2014; 57: 49-57.

Bolarin, F. M. and Bosa, S. (2015) 'Post Harvest Losses: A Dilemma in Ensuring Food Security in Nigeria', Journal of Natural Sciences Research, 5(7), pp. 2225-921. Available at: http://www.iiste.org/Journals/index.php/JNSR/article/viewFile/21502/22098.

Campus, A. et al. (2021) 'Strategies adopted by maize farmers to minimize post-harvest losses in Delta State , Nigeria', 17, pp. 237-256.

Food and Agriculture Organization of the United Nations. Toolkit: Reducing the food wastage footprint. Food and Agriculture Organization, Rome, Italy; 2013.

Joughin, J. and Kjær, A. M. (2010) 'The politics of agricultural policy reform: The case of Uganda', Forum for Development Studies. doi: 10.1080/08039410903558277.

Justina, K., Hirawaty, N. and Isima, K. (2019) 'Small-scale postharvest practices among plantain farmers and traders: A potential for reducing losses in rivers state, Nigeria', Scientific African. Elsevier B.V., 4, p. 
e00086. doi: 10.1016/j.sciaf.2019.e00086.

Kader, A. A. (2005) 'Increasing food availability by reducing postharvest losses of fresh produce', in Acta Horticulturae doi: 10.17660/ActaHortic.2005.682.296.

Kumar, D. and Kalita, P. (2017) 'Reducing Postharvest Losses during Storage of Grain Crops to Strengthen Food Security in Developing Countries', Foods. doi: 10.3390/foods6010008.

Mada, D. A. et al. (2014) 'Study on Impact of Post Harvest Losses and Post Harvest Technology in Ganye Southern Adamawa State-Nigeria', 14(2).

Management, P. et al. (2014) 'Reducing Food Losses in Sub-Saharan Africa', (April).

Mbata GN. 2013. Eradication of Global Hunger with Emphasis on Africa: Role in Post- Harvest Integrated Pest Management. Fulbright specialist lecture. The Federal University of Technology, Akure, Nigeria. 3- 17.

Naziri, D. et al. (2014) 'The diversity of postharvest losses in cassava value chains in selected developing countries', Journal of Agriculture and Rural Development in the Tropics and Subtropics, 115(2), pp. 111123.

Raut, R. D. et al. (2018) 'Modeling the drivers of post-harvest losses - MCDM approach', Computers and Electronics in Agriculture. Elsevier, 154(February 2017), pp. 426-433. doi: 10.1016/j.compag.2018.09.035.

Tefera, T. et al. (2011) 'The metal silo: An effective grain storage technology for reducing post-harvest insect and pathogen losses in maize while improving smallholder farmers' food security in developing countries', Crop Protection. doi: 10.1016/j.cropro.2010.11.015.

Udoh, A. J. (2009) 'Adoption of Post Harvest Crop Processing Machines for Increased Cassava and Maize Production: A Food Security Measure for Poor Income Farmers in Rural Nigeria', 9(3), pp. 78-83.

World, B. (2011) 'Missing food':, The Case of Postharvest Grain Losses in Sub-Saharan Africa. doi: $10.1038 /$ ncb2790.Role. 